\title{
The Role of the Reactive Species Involved in the Photocatalytic Degradation of HDPE Microplastics Using $\mathrm{C}, \mathrm{N}-\mathrm{TiO}_{2}$ Powders
}

\author{
Aranza Denisse Vital-Grappin ${ }^{1}\left(\right.$, Maria Camila Ariza-Tarazona ${ }^{2} \oplus$, Valeria Montserrat Luna-Hernández ${ }^{1}$, \\ Juan Francisco Villarreal-Chiu ${ }^{1,3, *}$, Juan Manuel Hernández-López ${ }^{1}\left(\mathbb{D}\right.$, Cristina Siligardi ${ }^{2}$ (I) \\ and Erika Iveth Cedillo-González ${ }^{1,2, * \mathbb{B}}$
}

Citation: Vital-Grappin, A.D.; ArizaTarazona, M.C.; Luna-Hernández, V.M.; Villarreal-Chiu, J.F.; HernándezLópez, J.M.; Siligardi, C.; CedilloGonzález, E.I. The Role of the Reactive Species Involved in the Photocatalytic Degradation of HDPE Microplastics Using $\mathrm{C}, \mathrm{N}-\mathrm{TiO}_{2}$ Powders. Polymers 2021, 13, 999. https://doi.org/10.3390/ polym13070999

Academic Editor: Jacopo La Nasa

Received: 28 February 2021

Accepted: 22 March 2021

Published: 24 March 2021

Publisher's Note: MDPI stays neutral with regard to jurisdictional claims in published maps and institutional affiliations.

Copyright: (C) 2021 by the authors Licensee MDPI, Basel, Switzerland. This article is an open access article distributed under the terms and conditions of the Creative Commons Attribution (CC BY) license (https:// creativecommons.org/licenses/by/ $4.0 /)$.
1 Universidad Autónoma de Nuevo León, Facultad de Ciencias Químicas, Av. Universidad S/N Ciudad Universitaria, San Nicolás de los Garza C.P. 66455, Nuevo León, Mexico; aranza.vitalgr@uanl.edu.mx (A.D.V.-G.); valeria.lunahrn@uanl.edu.mx (V.M.L.-H.); juan.hernandezlz@uanl.edu.mx (J.M.H.-L.)

2 Department of Engineering "Enzo Ferrari", University of Modena and Reggio Emilia, Via P. Vivarelli 10/1, 41125 Modena, Italy; mariacamila.arizatarazona@unimore.it (M.C.A.-T.); cristina.siligardi@unimore.it (C.S.)

3 Centro de Investigación en Biotecnología y Nanotecnología (CIByN), Facultad de Ciencias Químicas, Universidad Autónoma de Nuevo León, Parque de Investigación e Innovación Tecnológica, Km. 10 Autopista al Aeropuerto Internacional Mariano Escobedo, Apodaca 66629, Nuevo León, Mexico

* Correspondence: juan.villarrealch@uanl.edu.mx (J.F.V.-C.); ecedillo@unimore.it (E.I.C.-G.)

Abstract: Microplastics (MPs) are distributed in a wide range of aquatic and terrestrial ecosystems throughout the planet. They are known to adsorb hazardous substances and can transfer them across the trophic web. To eliminate MPs pollution in an environmentally friendly process, we propose using a photocatalytic process that can easily be implemented in wastewater treatment plants (WWTPs). As photocatalysis involves the formation of reactive species such as holes $\left(h^{+}\right)$, electrons $\left(e^{-}\right)$, hydroxyl $\left(\mathrm{OH}^{\bullet}\right)$, and superoxide ion $\left(\mathrm{O}_{2}{ }^{\bullet-}\right)$ radicals, it is imperative to determine the role of those species in the degradation process to design an effective photocatalytic system. However, for MPs, this information is limited in the literature. Therefore, we present such reactive species' role in the degradation of high-density polyethylene (HDPE) MPs using $\mathrm{C}, \mathrm{N}-\mathrm{TiO}_{2}$. Tert-butanol, isopropyl alcohol (IPA), Tiron, and $\mathrm{Cu}\left(\mathrm{NO}_{3}\right)_{2}$ were confirmed as adequate $\mathrm{OH}^{\bullet}, h^{+}, \mathrm{O}_{2}{ }^{\bullet-}$ and $e^{-}$scavengers. These results revealed for the first time that the formation of free $\mathrm{OH}^{\bullet}$ through the pathways involving the photogenerated $e^{-}$plays an essential role in the MPs' degradation. Furthermore, the degradation behaviors observed when $h^{+}$and $\mathrm{O}_{2}{ }^{\bullet-}$ were removed from the reaction system suggest that these species can also perform the initiating step of degradation.

Keywords: microplastics; HDPE; microbeads; photocatalysis; scavengers; $\mathrm{C}, \mathrm{N}-\mathrm{TiO}_{2}$; remediation; nanotechnology; plastic pollution; visible light photodegradation

\section{Introduction}

Microplastics (MPs) are defined as plastic particles with a diameter $\leq 5 \mathrm{~mm}$ and are categorized as primary or secondary according to their origin [1]. Primary MPs are manufactured explicitly to that particle size to be used in cosmetic or personal hygienic products [1]. On the other hand, secondary MPs are derived from large plastic items' fragmentation due to photolytic, mechanical, and biological degradation [1].

MPs pollution has increased so rapidly in recent years that it has become a global concern. Today, MPs can be found in a wide variety of sizes, shapes, and polymers in samples of soil, sand, air, water, wastewater, and snow all around the globe [1,2]. More importantly, due to their high specific surface area, MPs can adsorb persistent organic pollutants (POPs), hydrophobic organic contaminants (HOCs), pharmaceuticals, and heavy metals [1-3]. As MPs are frequently consumed by the biota present in aquatic and terrestrial ecosystems, these hazardous compounds can move easily through the trophic chain up 
to humans [1,2]. This has been evidenced by the presence of MPs in human stool [4] and even in the placenta [5]. Furthermore, the SARS-CoV-2 pandemic has increased MPs fibers' presence in the environment due to the inadequate disposal of single-use plastic face masks [6].

In this context, there is an urgent need to develop remediation technologies to dissipate MPs pollution. The current methodologies for this include physical removal, biodegradation, and chemical treatments $[7,8]$. These latter include photocatalysis, a process that has been widely used to mineralize recalcitrant organic pollutants in aqueous and gaseous environments [9].

There are several significant advantages of using photocatalysis as a remediation technology to solve MPs pollution. Firstly, MPs can be entirely mineralized to $\mathrm{CO}_{2}$ and water. Only a small fraction is known to be converted into innocuous or less toxic chemical substances $[10,11]$. Secondly, photocatalysis can easily be adapted to wastewater treatment plants (WWTPs), identified as a potential source of MPs to aquatic and terrestrial ecosystems $[1,2]$. By coupling MPs photocatalysis to WWTPs, not only could the MPs level in discharge waters be significantly reduced, but the harmful problems that these pollutants cause to their facilities could also be avoided (inhibitory effects on activated sludge flocs, reduction of the diversity of biological communities and decline of the abundance of crucial microorganisms [12]). Finally, the photocatalytic process can be regarded as environmentally friendly since it can be performed under visible or solar light. Simultaneously, the photocatalyst can be prepared using renewable raw materials, respecting the sixth, seventh and ninth principles of Green Chemistry.

Photocatalysis has recently been proven to degrade low-density polyethylene (LDPE), high-density polyethylene (HDPE), polystyrene (PS), and polypropylene (PP) MPs in aqueous solutions [10,11,13-19]. However, complete degradation of any of these plastics has not been reported yet. To improve or optimize MPs degradation and be able to achieve their mineralization, different criteria must be considered, such as the photocatalyst's properties, the pollutant's characteristics and the reaction conditions, and the potential role of reactive species such as holes $\left(h^{+}\right)$, electrons $\left(e^{-}\right)$, and reactive oxygen species (ROS) that are formed along the process and could participate in the degradation reaction.

To date, the role of these reactive species in MPs degradation has been lightly investigated. For example, Nabi et al. [18] reported the "solid phase" photodegradation of 400 nm PS MPs using a Triton X-100 derived $\mathrm{TiO}_{2}$ nanoparticle film with ethylenediaminetetraacetic acid (EDTA), tert-butyl alcohol (TBA), and anaerobic conditions to check the role of holes, hydroxyl radicals $\left(\mathrm{OH}^{\bullet}\right)$, and oxygen $\left(\mathrm{O}_{2}\right)$ in the degradation process. By monitoring the change in the PS particle's diameter using scanning electron microscopy (SEM) analysis, their experiments demonstrated that the $h^{+}$was the dominant active specie in their reaction system when submitted under UV light for $6 \mathrm{~h}$ [18]. On the other hand, Jiang et al. [11] evaluated the photocatalytic degradation of a $1 \mathrm{~g} / \mathrm{L}$ aqueous dispersion of HDPE MPs (200-250 $\mu \mathrm{m})$ using a hydroxy-rich bismuth oxychloride photocatalyst and visible light $(\lambda \geq 420 \mathrm{~nm})$. The role of $h^{+}, \mathrm{OH}^{\bullet}$, and superoxide ion radical $\left(\mathrm{O}_{2}{ }^{\bullet-}\right)$ in the degradation process was monitored by Fourier-transform infrared spectroscopy (FTIR) using methanol, isopropyl alcohol (IPA) and p-benzoquinone as scavengers. Results demonstrated that free $\mathrm{OH}^{\bullet}$ formed through the reaction of adsorbed water with surface hydroxyl was the main reaction group involved in the degradation process [11].

These studies suggested that different reactive species can promote MPs' degradation depending on the reaction conditions (solid- or aqueous-based reaction). However, there is still a need for a more in-depth analysis regarding the specific role that each one of those species may have on MPs degradation.

The present work is aimed to analyze the specific role of four reactive species in the photocatalytic degradation of primary HDPE MPs using $\mathrm{C}, \mathrm{N}-\mathrm{TiO}_{2}$ powders. To achieve this, tert-butanol, isopropyl alcohol, Tiron, and copper nitrate were used as $\mathrm{OH}^{\bullet}, h^{+}, \mathrm{O}_{2}{ }^{\bullet-}$ and $e^{-}$scavengers, respectively. The reactions were performed in an aqueous solution because of its relevance for applying this technology in WWTPs. The C,N-TiO 2 powders 
were chosen because they enable to perform the experiments in visible light and, get a better interaction between the dispersed photocatalyst and MPs [13]. It was found that all four species have an essential role in MPs degradation, suggesting for the first time that the photogenerated $e^{-}$plays an essential role in the photocatalytic degradation of HDPE MPs, mainly due to the formation of free $\mathrm{OH}^{\bullet}$. Furthermore, it was demonstrated that the initiating step on MPs degradation is performed by $\mathrm{OH}^{\bullet}, h^{+}$or $\mathrm{O}_{2}{ }^{\bullet-}$ species.

\section{Materials and Methods}

\subsection{MPs Obtainment and Characterization}

Primary HDPE MPs were obtained from a commercial facial scrub using the extraction methodology proposed by Napper et al. [20]. HDPE MPs particle size and morphology were determined by optical microscopy (OM) using a light microscope (DME, Leica, Wetzlar, Germany) with a microscope camera (ICC50 W, Leica, Wetzlar, Germany). Morphology was also investigated by SEM coupled with energy dispersive X-ray spectroscopy (EDS), using a Thermo-Fisher Scientific FEI E-SEM (Quanta-200, FEI Company, Hillsboro, OR, USA). Before the analysis, the samples were coated with a gold layer of $10 \mathrm{~nm}$. The type of polymer present in the sample was determined by attenuated total reflectance-Fouriertransform infrared spectroscopy (ATR-FTIR) in an infrared spectrometer (ALPHA II, Bruker, Ettlingen, Germany). The spectrum was collected by averaging 32 scans between 400 and $4000 \mathrm{~cm}^{-1}$ with a $4 \mathrm{~cm}^{-1}$ spectral resolution. The surface area was evaluated by nitrogen adsorption, using a surface area analyzer (Tristar II Plus 3.01, Micromeritics, Norcross, GA, USA) (bath temperature of $77.3 \mathrm{~K}$, equilibration interval of $5 \mathrm{~s}$, and degasification at $30{ }^{\circ} \mathrm{C}$ for $23 \mathrm{~h}$ ).

\section{2. $\mathrm{C}, \mathrm{N}-\mathrm{TiO}_{2}$ Preparation and Characterization}

The $\mathrm{C}, \mathrm{N}-\mathrm{TiO}_{2}$ semiconductor was prepared by the synthesis procedure reported by Zeng et al. [21], with some modifications already described in previous work [13]. The crystalline composition was determined by X-ray diffraction (XRD), using a diffractometer

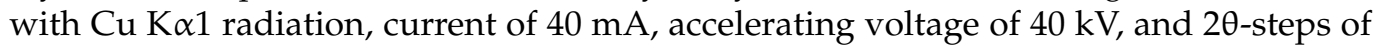
$0.023^{\circ}$ (D5000, SIEMENS, Munich, Germany). The chemical groups adsorbed in the semiconductor's surface were identified by ATR-FTIR (ALPHA II, Bruker, Ettlingen, Germany), using the analysis conditions reported in Section 2.1. The presence of nitrogen and carbon in the $\mathrm{TiO}_{2}$ semiconductor was confirmed by elemental analysis using a CHNS/O analyzer with acombustion temperature of $975^{\circ} \mathrm{C}$ and a reducing column with helium at $88^{\circ} \mathrm{C}$ (2400 Series II, PerkinElmer, Waltham, MA, USA). The bandgap $\left(E_{\mathrm{g}}\right)$ was calculated from the reflectance spectrum (Figure S1, Supplementary Materials) using the Kubelka-Munk equation (Equation S1). The spectrum was measured in an UV-vis/NIR spectrophotometer with $\mathrm{BaSO}_{4}$ (DEQ, Monterrey, Mexico) as reference material (V-670, JASCO, Tokyo, Japan). The microstructure was analyzed by field emission gun scanning electron microscopy (FEG-SEM)(Nova NanoSEM 450, FEI Company, Hilssboro, Oregon, USA). The BET surface area was evaluated by nitrogen adsorption, using a BET analyzer (Gemini 2380, Micromeritics, Norcross, GA, USA) (bath temperature of $77.3 \mathrm{~K}$, equilibration interval of $10 \mathrm{~s}$, and degasification at $110^{\circ} \mathrm{C}$ ).

\subsection{Photocatalytic Experiments in the Absence and Presence of Scavengers}

The photocatalytic experiments' reaction conditions were carried out according to our previous work, which demonstrated the photocatalytic degradation of HDPE MPs using the $\mathrm{C}, \mathrm{N}-\mathrm{TiO}_{2}$ material [13]. Therefore, photocatalysis without scavengers was conducted in a Batch-type glass reactor, using $50 \mathrm{~mL}$ of a $0.4 \mathrm{wt}$./ vol \% HDPE MPs dispersion (pH 3) and a $\mathrm{C}, \mathrm{N}-\mathrm{TiO}_{2}$ load of $200 \mathrm{mg}$. The reactor was placed in a closed reaction chamber equipped with a constant temperature bath (set at $0 \pm 2{ }^{\circ} \mathrm{C}$ ) and irradiated for $50 \mathrm{~h}$ with a Slim LED IP65 50 W visible LED lamp (ARE-006, ARTlite, New Delhi, India) placed at $25 \mathrm{~cm}$ from the sample $\left(57.2 \pm 0.3 \mathrm{~W} / \mathrm{m}^{2}\right)$. MPs were dispersed in the experiments by continuous stirring at $350 \mathrm{rpm}$. After photocatalysis, the residual (degraded) MPs 
were separated from the reaction system and washed twice with distilled water to remove potential $\mathrm{C}, \mathrm{N}-\mathrm{TiO}_{2}$ traces that could remain attached. The photocatalytic experiments with the scavengers were performed according to this methodology, but adding reagent grade tert-butanol (0.2 mol, DEQ, Monterrey, Mexico), IPA (0.5 mol, DEQ, Monterrey, Mexico), 4,5-dihydroxy-1,3-benzenedisulfonic acid disodium salt "tiron" ( $2.18 \times 10^{-5} \mathrm{~mol}$, Sigma Aldrich, Ciudad de México, México) or copper nitrate $\left(5.0 \times 10^{-3} \mathrm{~mol}\right.$, DEQ, Monterrey, Mexico) as scavengers [22,23] (Table 1). The quantities of each scavenger were chosen based on previous reports $[22,23]$ and, their concentrations were in excess respect to the HDPE MPs pollutants. Three replicates were performed for all the photocatalytic experiments, and the mean \pm S.D. values are reported.

Table 1. Chemical reagents used as $\mathrm{OH}^{\bullet}, h^{+}, \mathrm{O}_{2}{ }^{\bullet-}$ and $e^{-}$scavengers.

\begin{tabular}{cccc}
\hline Reagent & Scavenged Specie & $\boldsymbol{k}\left(\mathbf{M}^{-\mathbf{1}} \mathbf{s}^{-\mathbf{1}} \mathbf{)}^{\mathbf{a}}\right.$ & Reference \\
\hline Tert-butanol & $\mathrm{OH}^{\bullet}$ in bulk water & $6.2 \times 10^{8}$ & {$[22]$} \\
\hline \multirow{2}{*}{ IPA } & $h^{+}$ & NA & {$[22]$} \\
\cline { 2 - 4 } & $\mathrm{OH}^{\bullet}$ & $2 \times 10^{9}$ & {$[22]$} \\
\hline Tiron & $\mathrm{O}_{2}^{\bullet-}$ & $5 \times 10^{8}$ & {$[22]$} \\
\hline Copper nitrate & $e^{-}$ & $\mathrm{NA}$ & {$[23]$} \\
\hline
\end{tabular}

${ }^{a}$ Rate constant of the reaction between the reagent and the scavenged species.

To determine the reactive species' role in MPs photocatalysis, three analytical methods were used to monitor and confirm MPs degradation. These methods were particularly used as they are known to be effective independently of the presence of $\mathrm{C}, \mathrm{N}-\mathrm{TiO}_{2}$ traces. The first method used was gravimetry. This technique is commonly used due to its simplicity and represents a direct way to quantify the polymers' degradation [24]. As expected, no presence of traces of $\mathrm{C}, \mathrm{N}-\mathrm{TiO}_{2}$ in the residual MPs was detected by this method. All mass measurements were performed in an analytical balance (CY224C, ACZET, Mumbai, India) after 15, 30, and $50 \mathrm{~h}$ of photocatalysis. Changes in MPs' concentration were calculated and reported as wt./vol \%. After $50 \mathrm{~h}$ of photocatalysis, MPs degradation was monitored by FTIR, which can detect polar functional groups, such as ketones and ester carbonyls (typical of oxidative degradation pathways [24]). Nevertheless, as higher intensity of the carbonyl band does not always represent more plastic degradation, this signal has to be compared to second reference band [25]. Consequently, the extent of oxidation during MPs degradation was quantified by calculating their carbonyl index (CI). CI quantifies the absorbance change for the carbonyl stretch relative to the C-H stretching modes [24]. CI was defined as the carbonyl group's absorbance ratio around $1720 \mathrm{~cm}^{-1}$ to an internal thickness band as a reference peak at $1380 \mathrm{~cm}^{-1}$ [26] $\left(\mathrm{CI}=\mathrm{A}_{1720} / \mathrm{A}_{1380}\right)$. As the FTIR adsorption bands of $\mathrm{TiO}_{2}$ are located at the $439-754 \mathrm{~cm}^{-1}$ interval $[27,28]$, the presence of $\mathrm{C}, \mathrm{N}-\mathrm{TiO}_{2}$ traces in the residual MPs does not affect $\mathrm{CI}$ calculation. The CI changes of the whole set of samples were compared with the trend in the MPs' concentration. OM and SEM (secondary-electron imaging) were used to analyze the changes in the morphology of the MPs, again, with no interference from the presence of traces of $\mathrm{C}, \mathrm{N}-\mathrm{TiO}_{2}$. In conjunction with SEM, EDS was used to determine the incorporation of oxygen to the degraded MPs.

\section{Results}

\subsection{HDPE MPS and $\mathrm{C}, \mathrm{N}-\mathrm{TiO}_{2}$ Characterization}

As shown in Figure 1a, the blue microbeads extracted from the commercial facial scrub have an average size of $725 \pm 108 \mu \mathrm{m}$ (50 measurements). The FTIR analysis carried out on the microbeads (Figure $1 b$ ) revealed the characteristic vibrational bands of high-density polyethylene (HDPE), these being the bands at 2911 and $2846 \mathrm{~cm}^{-1}$ that correspond to the asymmetric and symmetric stretching vibrations of the $\mathrm{CH}_{2}$ group and the bands at 1463 and $719 \mathrm{~cm}^{-1}$ that correspond to the scissoring and rocking bending vibrations of the 
same group [27]. SEM micrographs demonstrated that the surface of the blue microbeads exhibited a homogeneous roughness, which may be related to their application as abrasive in facial scrubs (Figure 1c). Furthermore, some minimal roughness-related porosity was present, which leads to a surface area of $0.41 \pm 0.03 \mathrm{~m}^{2} / \mathrm{g}$ (Figure $1 \mathrm{~d}$ ). These results confirmed that the blue microbeads extracted from the commercial facial scrub are primary MPs of HDPE.
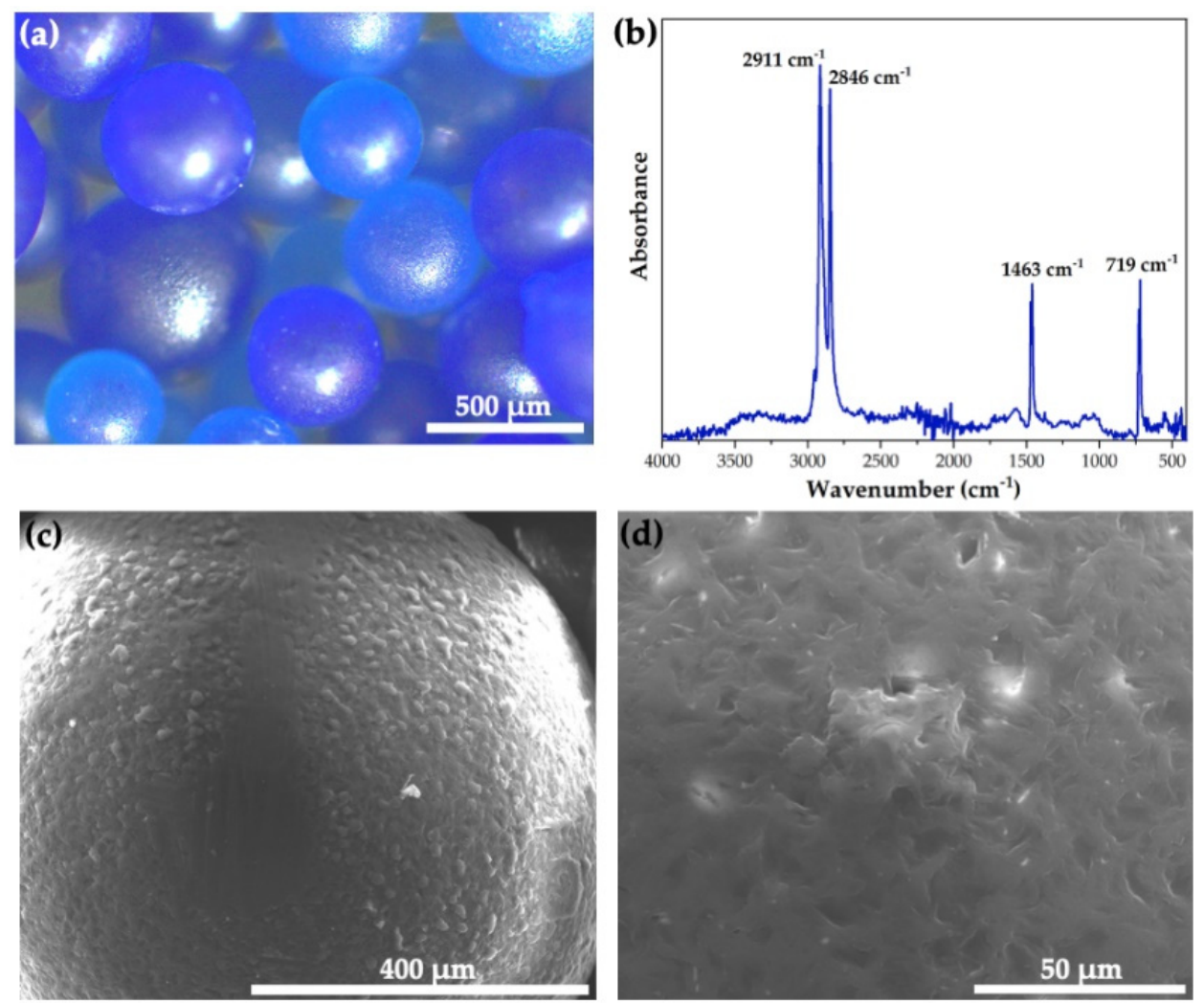

Figure 1. (a) Optical micrography, (b) FTIR spectrum, and (c,d) SEM micrographs of the as-extracted HDPE MPs.

For the $\mathrm{C}, \mathrm{N}-\mathrm{TiO}_{2}$ semiconductor, the XRD pattern (Figure 2a) showed that the semiconductor was mainly composed of the anatase polymorph of $\mathrm{TiO}_{2}$. However, two small peaks at $36^{\circ}$ and $44^{\circ}$ attributable to rutile $\mathrm{TiO}_{2}$ were also visible. Although anatase has a higher photocatalytic yield than rutile [29], it is known that the presence of rutile in mixed-phase $\mathrm{TiO}_{2}$ nanocomposites increases the photocatalytic activity due to the interfacial charge separation between anatase and rutile. Thus, inhibiting the recombination process of the photogenerated $h^{+}-e^{-}$pairs [30].

On the other hand, the FTIR analysis (Figure 2b) exhibited the absorption bands corresponding to the Ti-O-Ti bonds' stretching vibrations from the photocatalytic material, located at 439 and $754 \mathrm{~cm}^{-1}[27,28]$. The broad absorption band between 3450 and $3200 \mathrm{~cm}^{-1}$ was assigned to the $\mathrm{O}-\mathrm{H}$ bond's stretching vibration from adsorbed water. The adsorption bands at $1408 \mathrm{~cm}^{-1}$ and $1080 \mathrm{~cm}^{-1}$ were assigned to the vibrations of the Ti-N bond [31,32], while the band located $1627 \mathrm{~cm}^{-1}$ is usually related to the bending vibrations of the $\mathrm{N}-\mathrm{H}$ and $\mathrm{O}-\mathrm{H}$ bonds [32]. The additional elemental analysis confirmed that the semiconductor contained $0.41 \mathrm{wt}$. \% of nitrogen, along with $1.37 \mathrm{wt}$. \% of carbon (Table 2). The presence of these elements in the semiconductor's structure is known to promote a reduction of the bandgap of $\mathrm{TiO}_{2}$ from its standard value of $3.2 \mathrm{eV}$ [9] to $2.90 \mathrm{eV}$ (Figure S1), enabling the absorption of visible light of $428 \mathrm{~nm}$ (Table 2). 
(a)

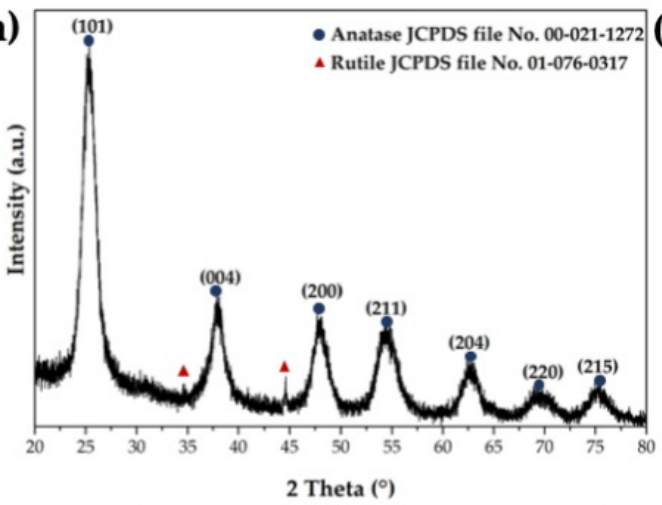

(c)

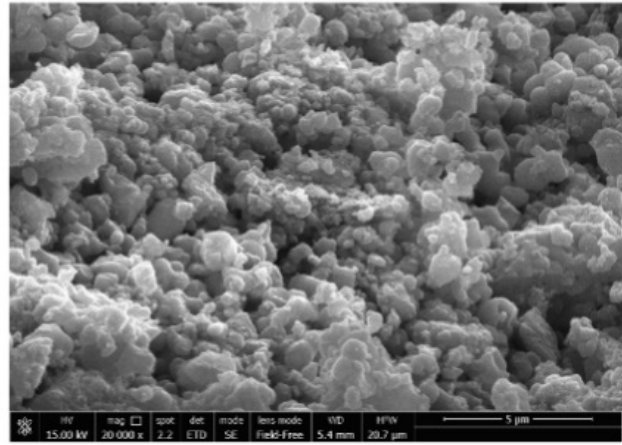

(b)

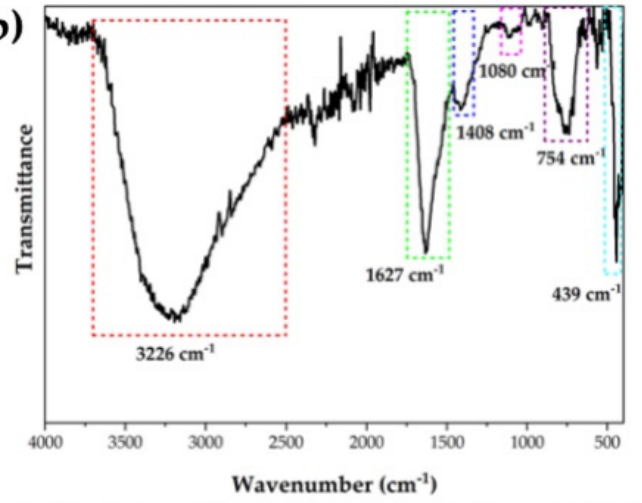

(d)

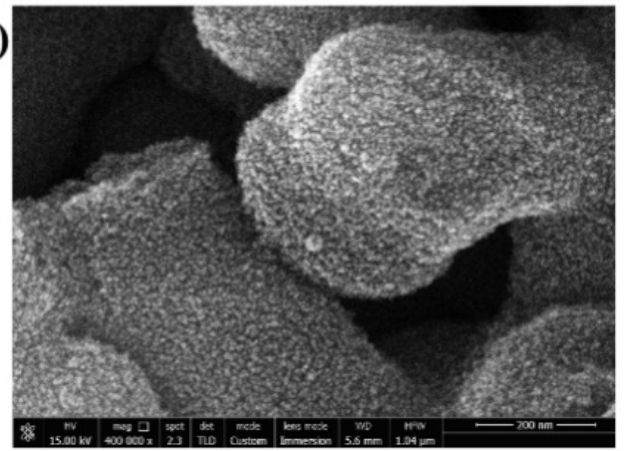

Figure 2. (a) XRD pattern, (b) FTIR spectrum, and (c,d) FEG-SEM micrographs of the $\mathrm{C}, \mathrm{N}-\mathrm{TiO}_{2}$ semiconductor.

Table 2. Properties of the $\mathrm{C}, \mathrm{N}-\mathrm{TiO}_{2}$ semiconductor.

\begin{tabular}{cc}
\hline Property & Value \\
\hline Carbon content $($ wt. \%) & 1.37 \\
\hline Nitrogen content (wt. \%) & 0.41 \\
\hline $\mathrm{E}_{\mathrm{g}}(\mathrm{eV})$ & 2.90 \\
\hline Wavelength of light absorption $(\mathrm{nm})$ & 428 \\
\hline BET surface area $\left(\mathrm{m}^{2} / \mathrm{g}\right)$ & $194.0 \pm 1.8$ \\
\hline Porosity type & Mesoporous \\
\hline
\end{tabular}

Figure 2c,d show the FEG-SEM micrographs of the $\mathrm{C}, \mathrm{N}-\mathrm{TiO}_{2}$ photocatalyst at different magnifications. At lower magnifications (Figure 2c), it can be observed that the semiconductor is formed by irregular particles that are ranged between 1 and $3 \mu \mathrm{m}$ in diameter, which promoted porosity due to their agglomeration. On the other hand, higher magnification (Figure 2d) exposed that these micrometric particles are formed by smaller particles of approximately $10 \mathrm{~nm}$ in diameter. Thus, the microstructure of the $\mathrm{C}, \mathrm{N}-\mathrm{TiO}_{2}$ semiconductor possesses a high surface area. This was demonstrated by BET analysis, which reported that the $\mathrm{C}, \mathrm{N}-\mathrm{TiO}_{2}$ semiconductor has a surface area of $194.0 \pm 1.8 \mathrm{~m}^{2} / \mathrm{g}$ (Table 2), being 3.88 times bigger than the surface area of commercial $\mathrm{TiO}_{2}\left(\right.$ Aeroxide $^{\circledR} \mathrm{P} 25$, $50 \mathrm{~m}^{2} / \mathrm{g}$ [22]). The isotherm obtained from the nitrogen absorption analysis (Figure S2) belongs to type IV, which corresponds to a mesoporous material according to the IUPAC classification (Table 2). The isotherm presented a hysteresis loop type H1, which is often associated with porous materials that consist of almost uniform agglomerated spheres [33], as observed in Figure 2d. 
3.2. Understanding the Practical and Mechanistic Issues of Photocatalytic Degradation of MPs in an Aqueous Medium

Photocatalysis of MPs using aqueous solutions and powder semiconductors should be carefully designed as it presents some inherent practical and mechanistic issues that may negatively affect degradation. As presented in Equation (1), irradiation of the semiconductor with energy higher than its bandgap generates $h^{+}$in its valence band and $e^{-}$ in the conduction band. If their recombination is avoided, $h^{+}$can oxidize organic pollutants $(\mathrm{P})$ to their radical cation (Equation (2)) or react with adsorbed water or hydroxyl groups $\left(\mathrm{OH}^{-}\right)$to generate $\mathrm{OH}^{\bullet}$ (Equations (3) and (4)), which in turn oxidize the adsorbed pollutants (Equation (5)) $[9,22,34]$. Photogenerated $e^{-}$reduce molecular oxygen to form $\mathrm{O}_{2}{ }^{\bullet-}$ (Equation (6)), which participates in the acid-base equilibrium with its protonated form (Equation (7)) [22]. As the $\mathrm{pK}_{\mathrm{a}}$ of $\mathrm{HO}_{2}{ }^{\bullet}$ is 4.6, the acidic form of $\mathrm{O}_{2}{ }^{\bullet-}$ may be the most abundant species in our reaction system ( $\mathrm{pH} 3)[22,35]$. Dismutation reactions of $\mathrm{HO}_{2}{ }^{\bullet}$ and $\mathrm{O}_{2}{ }^{\bullet-}$ generate $\mathrm{H}_{2} \mathrm{O}_{2}$ and $\mathrm{O}_{2}$ (Equations (8) and (9)) [9,22,35]. The generation of $\mathrm{H}_{2} \mathrm{O}_{2}$ during photocatalysis is a crucial step for further $\mathrm{OH}^{\bullet}$ formation in bulk water. Once formed, $\mathrm{H}_{2} \mathrm{O}_{2}$ can react with the photogenerated $e^{-}$(Equation (10)), $\mathrm{O}_{2}{ }^{\bullet-}$ (Equation (11)) or be decomposed by photolysis (Equation (12)) to form $\mathrm{OH}^{\bullet}$ [9]. The interaction of the hydroxyl radicals with the MPs should lead to the degradation of these tiny plastic pollutants (Equation (13)). It is essential to highlight that the reaction presented in Equation (10) only produces surface-adsorbed $\mathrm{OH}^{\bullet}$, while the reactions presented in Equations (11) and (12) can produce both surface-adsorbed and free $\mathrm{OH}^{\bullet}$ [9]. Additionally, the direct photolysis of $\mathrm{H}_{2} \mathrm{O}_{2}$ under visible light irradiation can be neglected due to its small molar absorption coefficient $\left(<1 \mathrm{M}^{-1} \mathrm{~cm}^{-1}\right.$ above $\left.300 \mathrm{~nm}\right)$ [23].

$$
\begin{gathered}
\text { Semiconductor }+h v \rightleftharpoons h^{+}+e^{-} \\
h^{+}+\mathrm{P} \rightleftharpoons \mathrm{P}^{\bullet+} \\
h^{+}+\mathrm{H}_{2} \mathrm{O}_{\text {ads }} \rightarrow \mathrm{OH}^{\bullet} \text { ads } \\
h^{+}+\mathrm{OH}^{-}{ }_{\text {ads }} \rightarrow \mathrm{OH}_{\text {ads }}^{\bullet} \\
\mathrm{P}+\mathrm{OH}_{\text {ads }} \rightarrow \text { Oxidation products } \\
e^{-}+\mathrm{O}_{2} \rightarrow \mathrm{O}_{2}^{\bullet-}\left(k=1.9 \times 10^{10} \mathrm{M}^{-1} \mathrm{~s}^{-1}\right) \\
\mathrm{HO}_{2}{ }^{\bullet} \rightleftharpoons \mathrm{H}^{+}+\mathrm{O}_{2}^{\bullet-}\left(\mathrm{pK}_{\mathrm{a}}=4.8\right) \\
2 \mathrm{HO}_{2}^{\bullet} \rightarrow \mathrm{H}_{2} \mathrm{O}_{2}+\mathrm{O}_{2} \\
2 \mathrm{O}_{2}{ }^{\bullet-}+2 \mathrm{H}^{+} \rightarrow \mathrm{H}_{2} \mathrm{O}_{2}+\mathrm{O}_{2} \\
\mathrm{H}_{2} \mathrm{O}_{2}+e^{-} \rightarrow \mathrm{OH}^{\bullet}+\mathrm{OH}^{-} \\
\mathrm{H}_{2} \mathrm{O}_{2}+\mathrm{O}_{2}^{\bullet-} \rightarrow \mathrm{OH}^{\bullet}+\mathrm{O}_{2}+\mathrm{OH}^{-} \\
\mathrm{H}_{2} \mathrm{O}_{2}+h v \rightarrow \mathrm{OH}^{\bullet}+\mathrm{OH}^{\bullet} \\
\mathrm{MPs}+\mathrm{OH}^{\bullet} \rightarrow \mathrm{Oxidation} \mathrm{products}^{\circ}
\end{gathered}
$$

As deduced by the previous reactions, the pollutant's interaction with the generated reactive species (through adsorption) is crucial to the photocatalytic process. When performing heterogeneous photocatalysis in an aqueous medium, the interaction between the pollutant and the semiconductor is usually achieved by the adsorption of the former at the surface of the photocatalyst. However, MPs pollutants cannot be adsorbed at the surface of the photocatalyst. As presented in Figure 3, the size of HDPE MPs limits their interaction with the powder semiconductor.

The MPs used in this work are nearly 241-fold the size of $\mathrm{C}, \mathrm{N}-\mathrm{TiO}_{2}$ biggest particles, precluding their adsorption on the semiconductor and limiting their oxidation by $h^{+}$and adsorbed $\mathrm{OH}^{\bullet}$. However, degradation may still be promoted whether the semiconductor is used in the form of a powder dispersion. As shown in Figure 3, the C,N- $\mathrm{TiO}_{2}$ semiconductor 
forms a coating on the HDPE MPs' surface [13]. Nonetheless, the MPs' coverage with $\mathrm{C}, \mathrm{N}-\mathrm{TiO}_{2}$ may be limited by the low porosity and surface area of the HDPE microbeads.

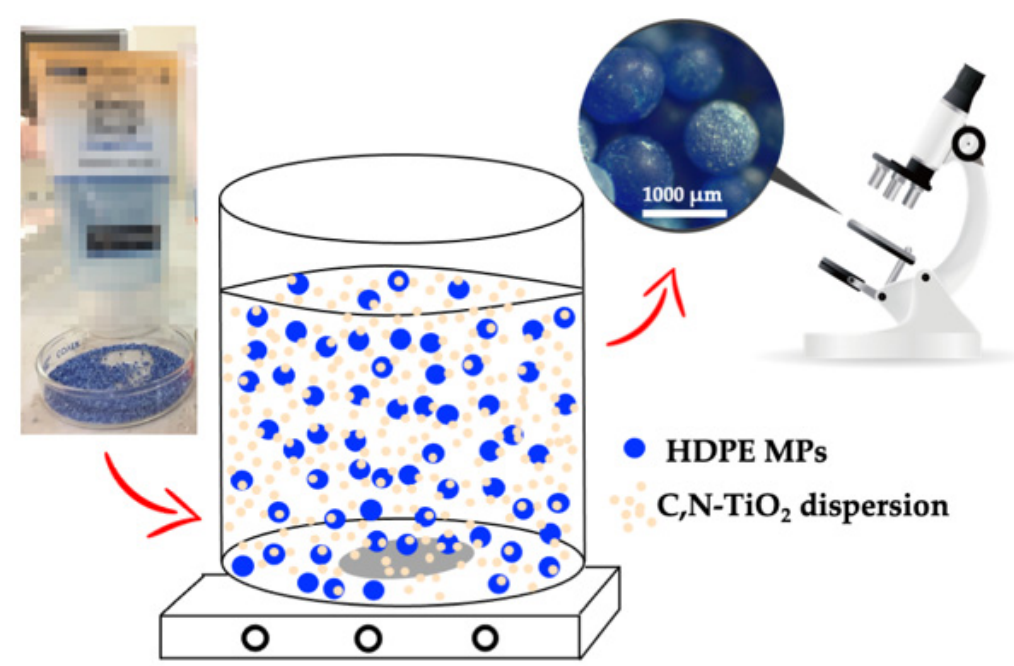

Figure 3. Adsorption of the $\mathrm{C}, \mathrm{N}-\mathrm{TiO}_{2}$ semiconductor in the surface of HDPE MPs.

\subsection{Effect of Free $\mathrm{OH}^{\bullet}$ on HDPE MPs Photocatalytic Degradation}

The interaction between the HDPE MPs and the $\mathrm{C}, \mathrm{N}-\mathrm{TiO}_{2}$ powder semiconductor is limited when photocatalysis is performed in an aqueous medium. Thus, it is very likely that most of the photocatalytic degradation of MPs is mainly conducted by the free $\mathrm{OH}^{\bullet}$ radicals present in the bulk of the medium. To determine the free $\mathrm{OH}^{\bullet}$ contribution in HDPE MPs degradation, photocatalysis was carried out in the absence and presence of tert-butanol as $\mathrm{OH}^{\bullet}$ scavenger.

Figure 4 presents the degradation plot for the visible-light photocatalysis of HDPE $\mathrm{MPs}$ by $\mathrm{C}, \mathrm{N}-\mathrm{TiO}_{2}$ in the absence and presence of tert-butanol. The black curve shows that without scavenger, i.e., when free $\mathrm{OH}^{\bullet}$ are present in the reaction system, the MPs' concentration was reduced by $71.77 \%$. As previously reported, degradation at these conditions was related to the increase of the MPs' surface area due to their fragmentation at $0{ }^{\circ} \mathrm{C}$ and the effect of acidic $\mathrm{pH}$ in the plastic degradation mechanism and the semiconductor deagglomeration [13]. The red curve of Figure 4 shows that the inhibition of the reaction between HDPE MPs and free $\mathrm{OH}^{\bullet}\left(k\right.$ for the tert-butanol/ $\mathrm{OH}^{\bullet}$ reaction is $6.2 \times 10^{8} \mathrm{M}^{-1} \mathrm{~s}^{-1}$, Table 1) dramatically reduces the degradation of MPs. The MPs concentration reduction passed from $71.77 \%$ at normal conditions to $1.98 \%$ when tert-butanol is present in the reaction system. This behavior indicates that free $\mathrm{OH}^{\bullet}$-mediated oxidation processes are the predominant pathways leading to the HDPE MPs' degradation. This result is in good agreement with that obtained by Jiang et al. [11] and with the LDPE and PP MPs degradation pathways suggested by the research group of J. Dutta [10,36]. For this work, the reaction systems characteristics discussed in Section 3.2 suggest that oxidation of HDPE MPs by $\mathrm{C}, \mathrm{N}-\mathrm{TiO}_{2}$ is promoted $\mathrm{OH}^{\bullet}$ formation through the reaction pathways involving the photogenerated $e^{-}$(Equations (6)-(11)). The fact that some degradation was still detected at these reaction conditions was related to the deposition of the $\mathrm{C}, \mathrm{N}-\mathrm{TiO}_{2}$ powders on the MPs' surface (Figure 3), a phenomenon that may facilitate the direct oxidation of the HDPE microbeads with the photogenerated $h^{+}$(Equation (2)). To test this hypothesis, photocatalytic experiments using IPA as an $h^{+}$scavenger were performed. 


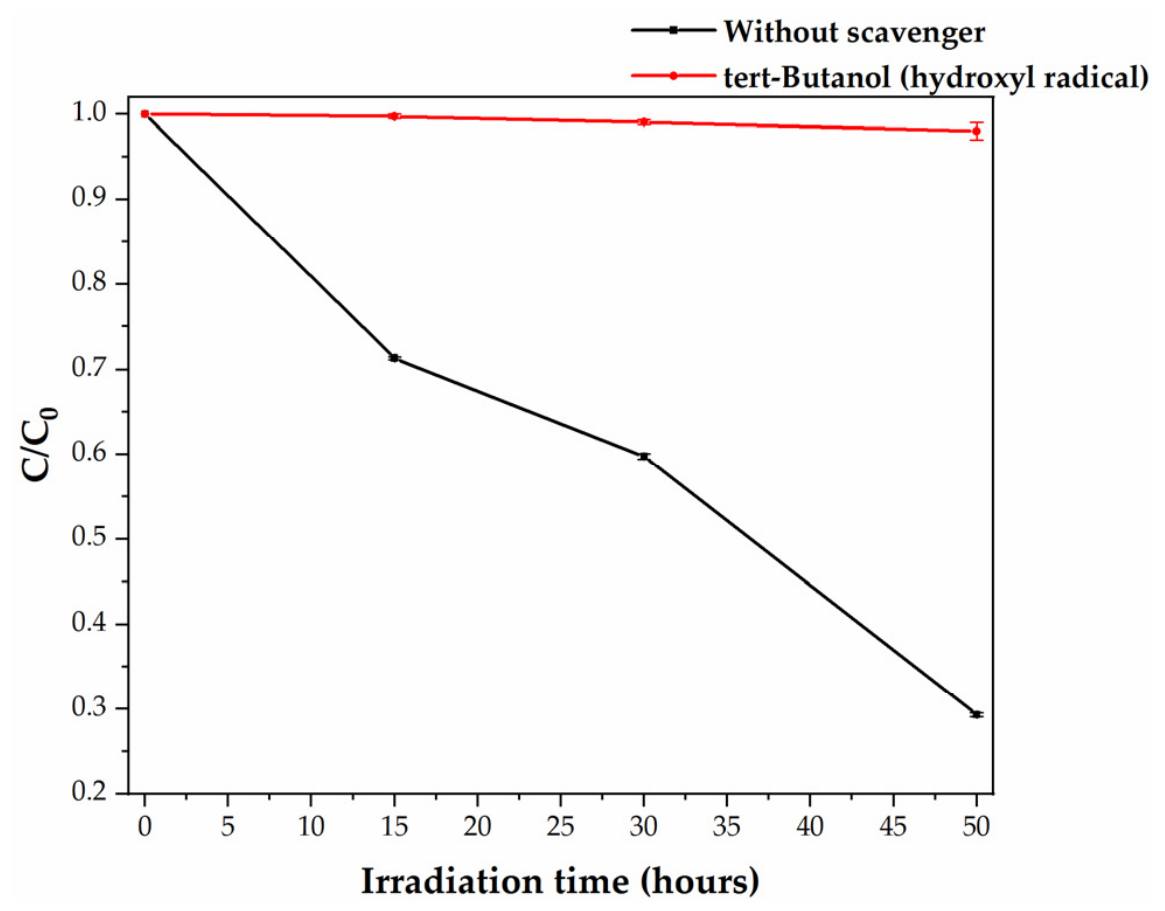

Figure 4. Visible-light photocatalytic degradation of HDPE MPs by $\mathrm{C}, \mathrm{N}-\mathrm{TiO}_{2}$ in the absence and presence of tert-Butanol as free $\mathrm{OH}^{\bullet}$ scavenger.

\subsection{Effect of $h^{+}$on HDPE MPs Photocatalytic Degradation}

Holes are the primary oxidizing species in photocatalytic reactions [9]. Although they are not usually related to plastic degradation by photocatalysis, photogenerated $h^{+}$can carry out the direct oxidation of organics when these compounds can act as electron donors $[9,37]$. For example, Ueckert et al. reported that photoreforming of poly(ethylene terephthalate) (PET) and poly(lactic acid) (PLA) could be carried out by carbon nitride/nickel phosphide $\left(\mathrm{CN}_{\mathrm{x}} \mid \mathrm{Ni}_{2} \mathrm{P}\right)$ photocatalyst [38]. By performing this process in the presence of terephthalic acid (TPA) as an $\mathrm{OH}^{\bullet}$ scavenger, authors found that $\mathrm{OH}^{\bullet}$ plays a minimal role in the oxidation of plastics and that photoreforming instead proceeds via direct $h^{+}$transfer between the catalyst and the substrate [38]. Here, to determine the contribution of $h^{+}$in the degradation of HDPE MPs, photocatalysis was carried out in the presence of IPA as an $h^{+}$ scavenger [22]. As tert-butanol, IPA can also act as $\mathrm{OH}^{\bullet}$ scavenger $\left(k=2 \times 10^{9} \mathrm{M}^{-1} \mathrm{~s}^{-1}\right.$, Table 1). However, due to its smaller size, IPA presents strong dissociative and nondissociative chemisorption on $\mathrm{TiO}_{2}$ [39]. Thus, adsorbed IPA acts as an electron donor and is oxidized by $h^{+}$.

Figure 5 presents the degradation plot for the visible-light photocatalysis of HDPE MPs by $\mathrm{C}, \mathrm{N}-\mathrm{TiO}_{2}$ in the absence and presence of IPA.

The blue curve of Figure 5 shows that when IPA is added to the reaction system, MPs' photocatalytic removal is inhibited. IPA decreases MPs degradation by adsorbing on the semiconductor surface, reacting with the photogenerated $h^{+}$, and avoiding Reaction 2 . As IPA also eliminates $\mathrm{OH}^{\bullet}$ from the reaction system, this result suggests that HDPE MPs are oxidized by the free $\mathrm{OH}^{\bullet}$ and directly by the photogenerated $h^{+}$. These species can react with the free electron-containing ending groups of the PE chain [40] through the photo-Kolbe reaction [41] (Equation (14)).

$$
\mathrm{RCOO}^{-}+h^{+} \rightarrow \mathrm{R}^{\bullet}+\mathrm{CO}_{2}
$$




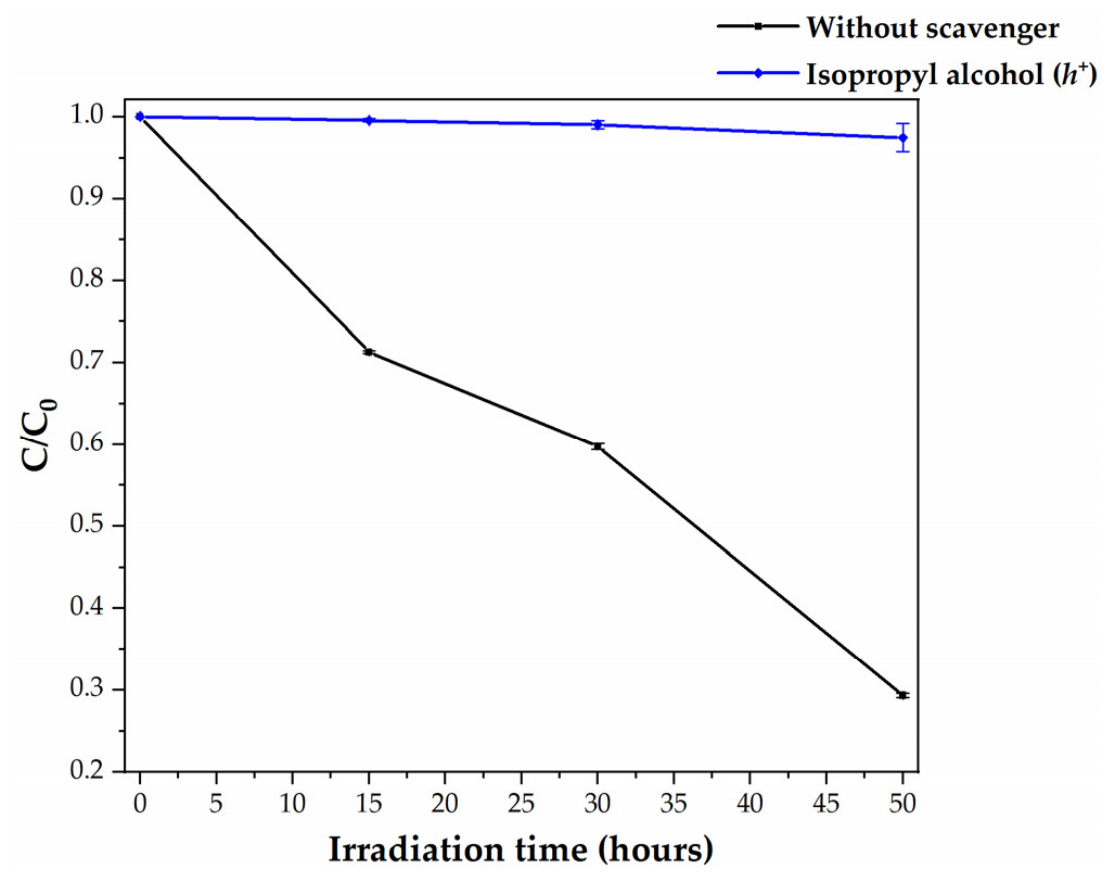

Figure 5. Visible-light photocatalytic degradation of HDPE MPs by $\mathrm{C}, \mathrm{N}-\mathrm{TiO}_{2}$ in the absence and presence of IPA as $h^{+}$and $\mathrm{OH}^{\bullet}$ scavenger.

At these reaction conditions (similar to those reported in Section 3.3 for tert-butanol scavenger), low degradation of the HDPE MPs was detected (HDPE concentration was reduced by $2.53 \%$ ). This result was related to the deposition of the $\mathrm{C}, \mathrm{N}-\mathrm{TiO}_{2}$ powders on the MPs' surface, a phenomenon that in this system (without $h^{+}$and $\mathrm{OH}^{\bullet}$ ) may facilitate the HDPE oxidation microbeads with $\mathrm{O}_{2}{ }^{\bullet-}$. As recombination of the photogenerated $h^{+}-e^{-}$ pairs was avoided by scavenging $h^{+}$with IPA, the reaction presented in Equation (6) is favored, and $\mathrm{O}_{2}{ }^{\bullet-}$ is expected to be present in the reaction system. As $\mathrm{OH}^{\bullet}, \mathrm{O}_{2}{ }^{\bullet-}$ is often believed to play an essential role in initiating the polyethylene degradation process by attacking the polymeric chain $[17,26]$. To test this hypothesis, photocatalytic experiments using Tiron as an $\mathrm{O}_{2}{ }^{\bullet-}$ scavenger were performed.

\subsection{Effect of $\mathrm{O}_{2}{ }^{\bullet-}$ on HDPE MPs Photocatalytic Degradation}

The role of $\mathrm{O}_{2}{ }^{\bullet-}$ on the photocatalytic degradation organics in water is frequently evaluated using $\mathrm{p}$-benzoquinone scavenger ( $k$ for $\mathrm{p}$-benzoquinone $/ \mathrm{O}_{2}{ }^{\bullet-}$ reaction is 0.9-1 $\times 10^{9} \mathrm{M}^{-1} \mathrm{~s}^{-1}$ ) [22]. However, p-benzoquinone does not only react with $\mathrm{O}_{2}{ }^{\bullet-}$, but also with $e^{-}\left(k=1.35 \times 10^{9} \mathrm{M}^{-1} \mathrm{~s}^{-1}\right)$ and $\mathrm{OH}^{\bullet}\left(k=6.6 \times 10^{9} \mathrm{M}^{-1} \mathrm{~s}^{-1}\right)$ [22]. The use of p-benzoquinone as an $\mathrm{O}_{2}{ }^{\bullet-}$ scavenger has other drawbacks. When photoexcited with wavelengths above $310 \mathrm{~nm}$, p-benzoquinone produces singlet oxygen $\left({ }^{1} \mathrm{O}_{2}\right)$ [42], which may contribute to the oxidation of organic molecules [9]. On the other hand, Garg et al. have postulated that quinones in natural organic matter are subjected to photolysis under sunlight, generating $\mathrm{O}_{2}{ }^{\bullet-}$, which further evolves to $\mathrm{H}_{2} \mathrm{O}_{2}$ and $\mathrm{OH}^{\bullet}$ [43]. Tiron was chosen as $\mathrm{O}_{2}{ }^{\bullet-}$ scavenger ( $k$ for Tiron $/ \mathrm{O}_{2}{ }^{\bullet-}$ reaction is $5 \times 10^{8} \mathrm{M}^{-1} \mathrm{~s}^{-1}$, Table 1 ) due to the previous motivations.

Figure 6 presents the degradation plot for the visible-light photocatalysis of HDPE MPs by $\mathrm{C}, \mathrm{N}-\mathrm{TiO}_{2}$ in the absence and presence of Tiron. The pink curve of Figure 6 shows that when Tiron is added to the reaction system, MPs' photocatalytic removal is reduced but not completely inhibited (MPs' concentration was reduced by $37.98 \%$ ). This inhibition is in good agreement with the previously proposed photocatalytic degradation pathways of LDPE and PP MPs [10,36]. To explain the partial inhibition of photocatalysis, three phenomena should be taken into account: The absence of (i) $\mathrm{O}_{2}{ }^{\bullet-}$ and (ii) $\mathrm{O}_{2}{ }^{\bullet-}$-derived $\mathrm{OH}^{\bullet}$ in the reaction system and (iii) the presence of adsorbed $h^{+}$on the $\mathrm{C}, \mathrm{N}-\mathrm{TiO}_{2}$ surface. 
First, some reports indicate that $\mathrm{O}_{2}{ }^{\bullet-}$ is involved in the direct oxidations of organic molecules that can act as a proton source $[9,44]$, as $\mathrm{O}_{2}{ }^{-}$can react with a proton donor to form $\mathrm{HO}_{2} \bullet$ (Equation (15)) [44]:

$$
\mathrm{O}_{2}^{\bullet-}+\mathrm{HX} \rightleftharpoons \mathrm{HO}_{2}^{\bullet}+\mathrm{X}^{-}
$$

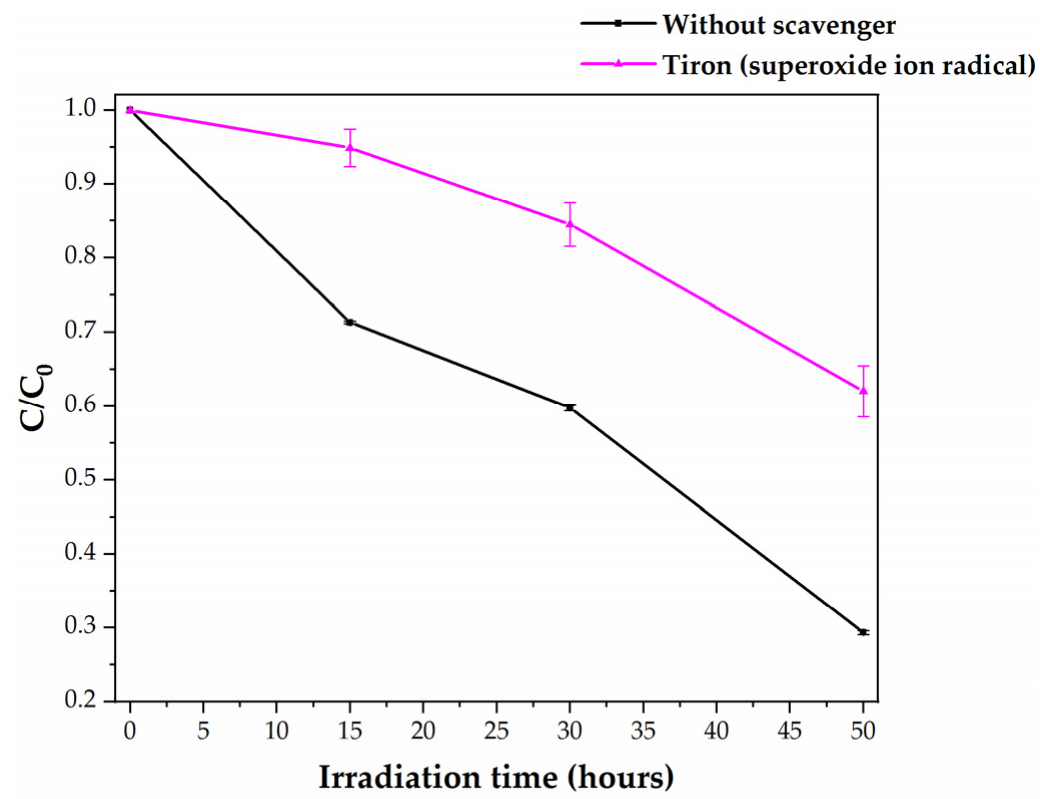

Figure 6. Visible-light photocatalytic degradation of HDPE MPs by $\mathrm{C}, \mathrm{N}-\mathrm{TiO}_{2}$ in the absence and presence of Tiron as $\mathrm{O}_{2}{ }^{\bullet-}$ scavenger.

Here, $\mathrm{O}_{2}{ }^{\bullet-}$ may promote the initiation step of PE oxidation by the abstraction of a proton of the polymeric chain (see Scheme 1 in Section 3.7). Therefore, degradation is in part inhibited when this species is not present in the reaction system. However, when $\mathrm{O}_{2}{ }^{\bullet-}$ reacts with Tiron, the acid-based equilibrium presented in Equation (7) is perturbed. As a consequence, the formation of $\mathrm{H}_{2} \mathrm{O}_{2}$ through Equations (8) and (9) is avoided. As $\mathrm{H}_{2} \mathrm{O}_{2}$ further evolves to $\mathrm{OH}^{\bullet}$ through Equations (10) and (11), this specie is not expected to be present in this particular reaction system. As the role of the $\mathrm{OH}^{\bullet}$ in the MPs degradation has been ruled out in Section 3.3, the decrease in degradation is explained by its absence from the reaction system. Consequently, this suggests that $\mathrm{O}_{2}{ }^{\bullet-}$ plays an essential role in HDPE MPs photocatalytic degradation by extracting protons from the PE chain and their conversion to $\mathrm{H}_{2} \mathrm{O}_{2}$ and $\mathrm{OH}^{\bullet}$. Lastly, the reduction of the HDPE degradation (instead of the complete inhibition) of Figure 6 confirms MPs' oxidation by the adsorbed $h^{+}$species through Reaction 2 . As ${ }^{1} \mathrm{O}_{2}$ cannot be present in the reaction system because it is formed through oxidation of the absent $\mathrm{O}_{2}{ }^{\bullet-}$ by the adsorbed $h^{+}$[9], the only plausible path for MPs degradation in the presence of Tiron is the direct oxidation by $h^{+}$. The lower degradation of MPs concerning the experiment without scavenger (black curve) was related to the limited deposition of $\mathrm{C}, \mathrm{N}-\mathrm{TiO}_{2}$ powders on the MPs. The crucial role of the $\mathrm{O}_{2}{ }^{\bullet-}$ in the photocatalytic degradation of HDPE MPs presented here differs from the result obtained by Juang et al. [11], where the absence of this reactive species in their system did not affect the degradation of HDPE MPs by BiOCl photocatalyst. This difference can be related to the use of p-benzoquinone as an $\mathrm{O}_{2}{ }^{\bullet-}$ scavenger [11], which can lead to the formation of ${ }^{1} \mathrm{O}_{2}$ [42], $\mathrm{H}_{2} \mathrm{O}_{2}$ [43] and $\mathrm{OH}^{\bullet}$ [43] in the reaction system. From these, $\mathrm{OH}^{\bullet}$ was observed to be the main specie that promotes degradation [11]. 


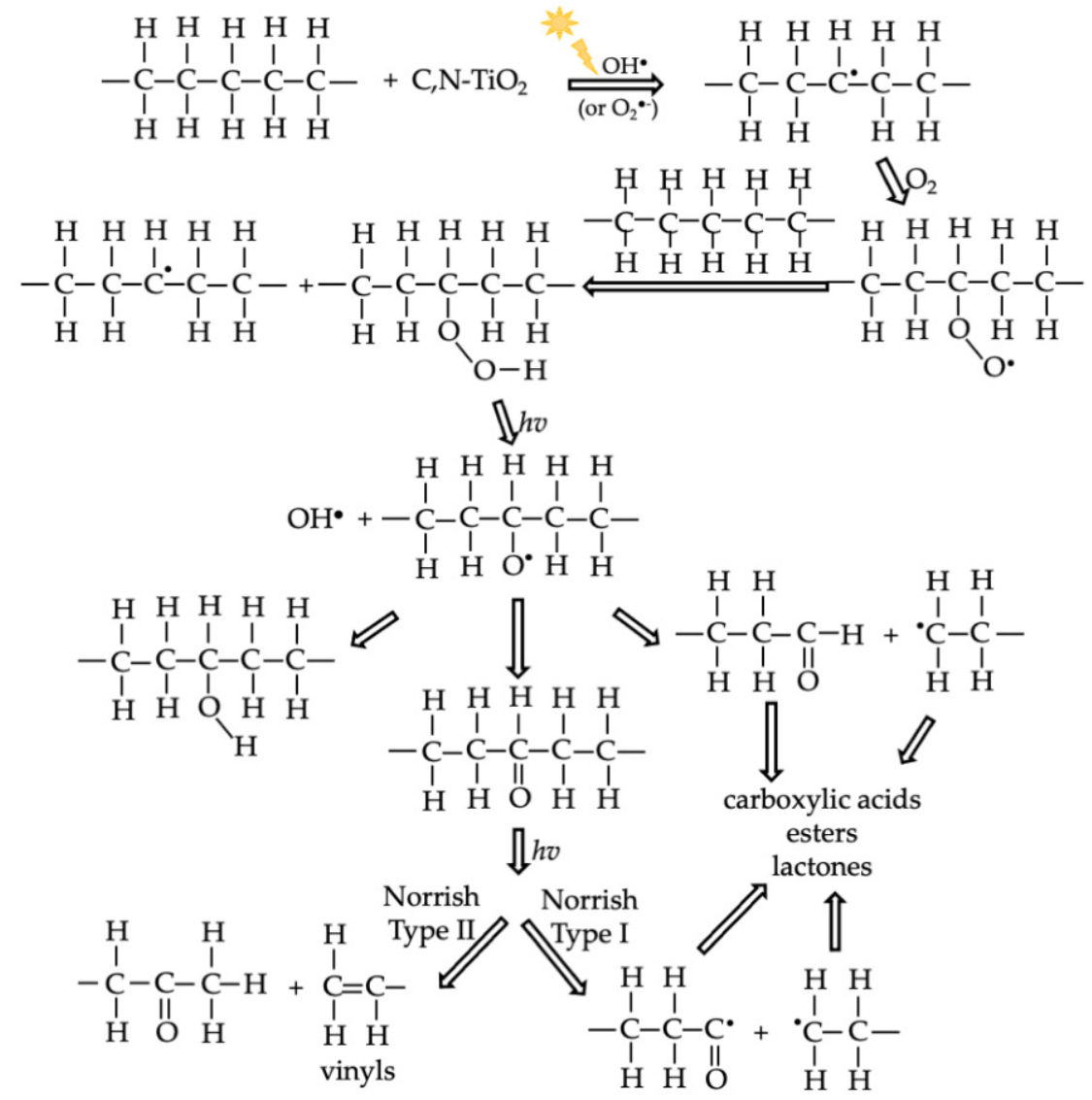

Scheme 1. Proposed mechanism for HDPE MPs photocatalytic degradation with $\mathrm{C}, \mathrm{N}-\mathrm{TiO}_{2}$.

\subsection{Effect of $e^{-}$on HDPE MPs Photocatalytic Degradation}

Copper nitrate was used to determine the role of the photogenerated $e^{-}$in the HDPE degradation. This reagent was used because the adsorption of the $\mathrm{NO}_{3}{ }^{-}$anions on the surface of $\mathrm{TiO}_{2}$ is known to be weak [23]. Figure 7 presents the degradation plot for the visible-light photocatalysis of HDPE MPs by $\mathrm{C}, \mathrm{N}-\mathrm{TiO}_{2}$ in the absence and presence of $\mathrm{Cu}\left(\mathrm{NO}_{3}\right)_{2}$.

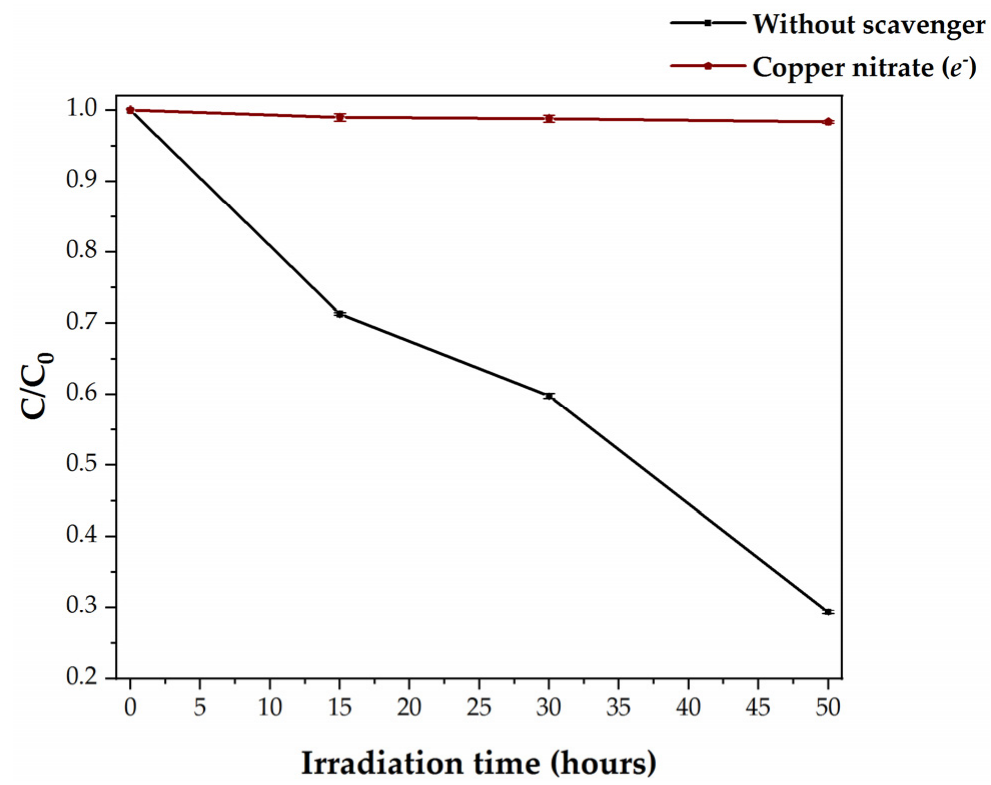

Figure 7. Visible-light photocatalytic degradation of HDPE MPs by $\mathrm{C}, \mathrm{N}-\mathrm{TiO}^{2}$ in the absence and presence of copper nitrate as an $e^{-}$scavenger. 
As observed in the bordeaux colour curve of Figure 7, the presence of copper nitrate in the reaction system inhibits MPs degradation. This result can be explained by analyzing the critical steps of the photocatalytic mechanism where photogenerated $e^{-}$participates. As $\mathrm{Cu}^{2+}$ cation adsorbs in the surface of $\mathrm{C}, \mathrm{N}-\mathrm{TiO}_{2}$, it reacts with the $e^{-}$, inhibiting the formation of $\mathrm{O}_{2}{ }^{\bullet-}$ through the reaction presented in Equation (6) [23]. As explained previously, the absence of $\mathrm{O}_{2}{ }^{\bullet-}$ inhibits the generation of $\mathrm{H}_{2} \mathrm{O}_{2}$ and its further conversion into free $\mathrm{OH}^{\bullet}$ (Equations (6)-(9)). Furthermore, removing $e^{-}$from the reaction system inhibits the reduction of $\mathrm{H}_{2} \mathrm{O}_{2}$ to $\mathrm{OH}^{\bullet}$ (Equation (10)). This latter is a key element for the degradation of HDPE MPs by photocatalysis with $\mathrm{C}, \mathrm{N}-\mathrm{TiO}_{2}$. Since the quenching of $e^{-}$ with copper nitrate avoids $h^{+}-e^{-}$recombination, the low degradation of the MPs at these conditions $(1.64 \%)$ was attributed to the adsorbed $h^{+}$and their interaction with the MPs.

Figure 8 presents the optical micrographs of the HDPE MPs after visible-light photocatalytic degradation by $\mathrm{C}, \mathrm{N}-\mathrm{TiO}_{2}$ in the four scavengers' presence. The MPs subjected to photocatalysis in reaction media without $\mathrm{OH}^{\bullet}, h^{+}$, and $e^{-}$show the same morphology as the as-extracted microplastics of Figure $2 \mathrm{a}$. On the other hand, the photocatalytically degraded MPs in the absence of $\mathrm{O}_{2}{ }^{\bullet-}$ are highly disintegrated (Figure 8c), confirming plastic degradation [45].

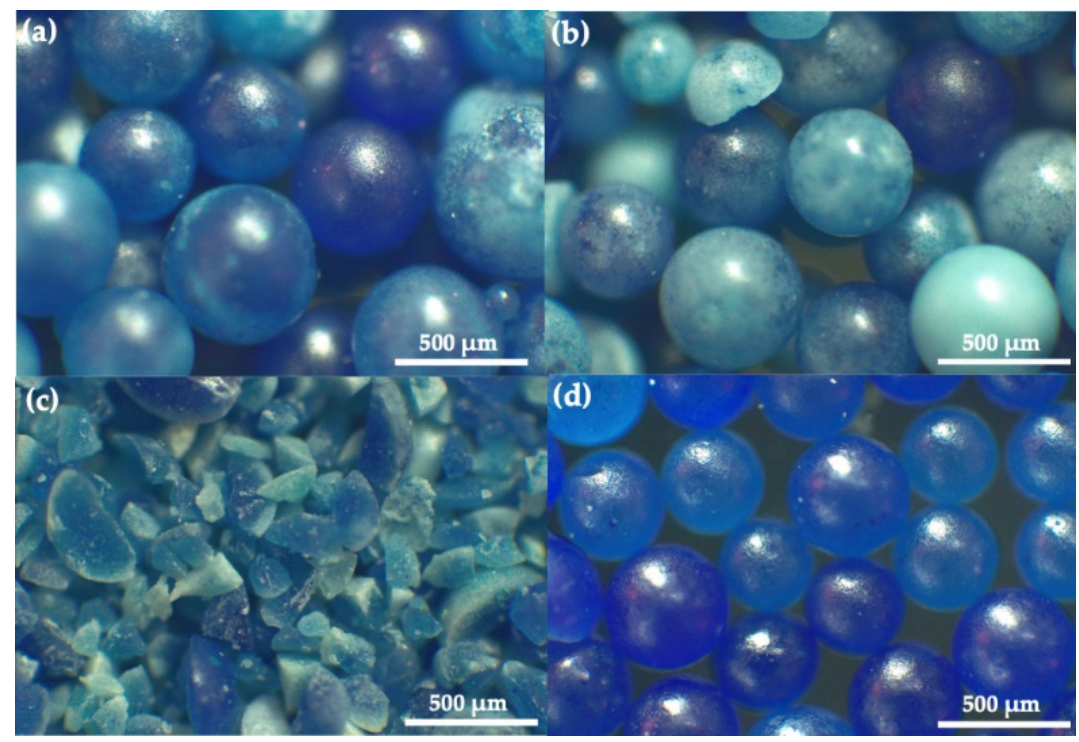

Figure 8. Optical micrographs of the HDPE MPs after visible-light photocatalytic degradation for $50 \mathrm{~h}$ by $\mathrm{C}, \mathrm{N}-\mathrm{TiO}_{2}$ in the presence of (a) tert-Butanol, (b) isopropyl alcohol (c) Tiron, and (d) copper nitrate scavengers.

A deeper insight into the changes of the MPs morphology was determined by SEM (Figure 9). The SEM micrographs of the microbeads subjected to photocatalysis without $\mathrm{OH}^{\bullet}, h^{+}$, and $e^{-}$show the same rough surface as the as-extracted microplastics of Figure $2 \mathrm{~d}$, while the MPs that were degraded in the absence of $\mathrm{O}_{2}{ }^{--}$present a slightly smoother surface. The loss of roughness was related to the degradation of the more external surface of the HDPE MPs by the adsorbed $h^{+}$, as most plastics degrade first at the polymer surface because it is exposed and available for the chemical attack $[13,45]$.

EDS chemical microanalysis of the as-extracted and degraded MPs are presented in Figures S3 and S4, respectively. In both cases, the signal from gold corresponds to the conductive layer deposited during sample preparation. For the as-extracted MPs, the EDS spectra were taken from several microbeads and they present the intense signal of carbon from polyethylene polymer. As observed in Figure S3, the oxygen signal is practically absent from this sample, indicating that the as-extracted MPs are not oxidated. The EDS spectra from Figure S4 correspond to the MPs subjected to photocatalysis for $50 \mathrm{~h}$ at $\mathrm{pH} 3$ and $0{ }^{\circ} \mathrm{C}$, without scavengers. The oxygen signal is present in all the spectra. However, the EDS analysis interpretation must take into account both oxidation and the presence 
of $\mathrm{C}, \mathrm{N}-\mathrm{TiO}_{2}$ on the plastic's surface, as both contribute to the oxygen signal. Figure S5 presents a higher magnification micrograph of the same sample, where the photocatalyst residues are visible. By taking into account the stoichiometry of $\mathrm{TiO}_{2}$, the EDS analysis presented in Table S1 demonstrates that the presence of oxygen in this sample can be related to plastic oxidation (spectrum 6), the semiconductor (spectra 1 and 2) or a combination of both (spectra 3-5).

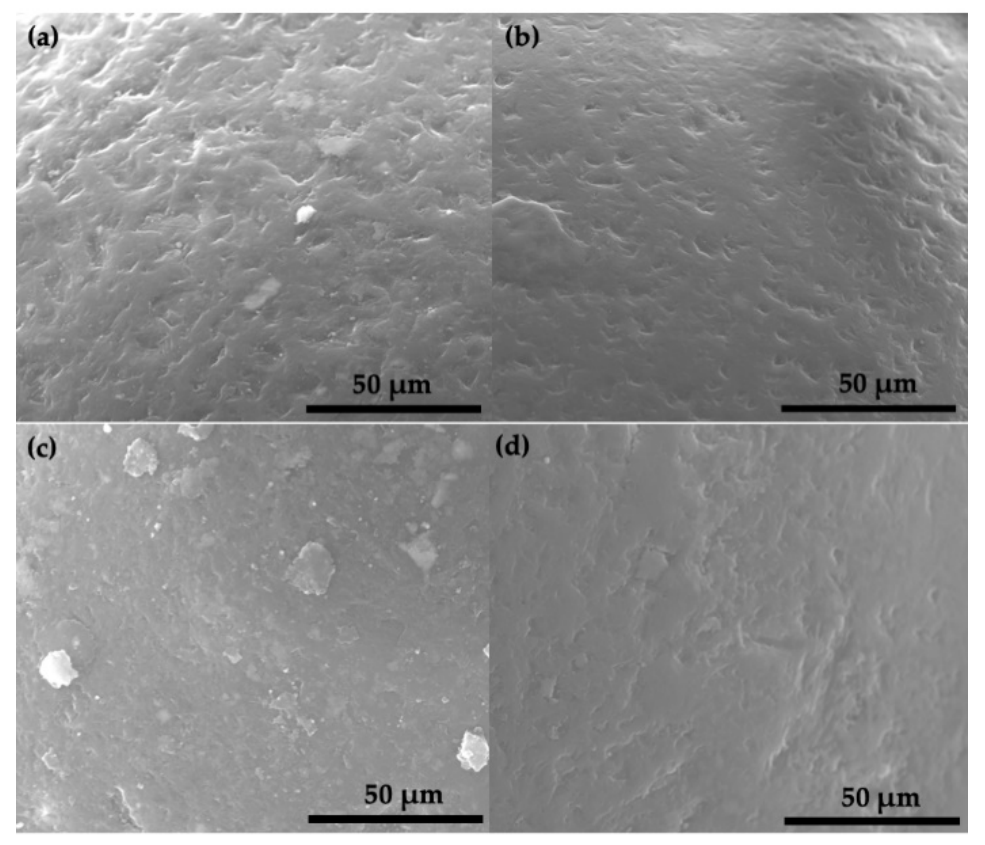

Figure 9. SEM micrographs of the HDPE MPs after visible-light photocatalytic degradation for $50 \mathrm{~h}$ by $\mathrm{C}, \mathrm{N}-\mathrm{TiO}_{2}$ in the (a) tert-Butanol, (b) isopropyl alcohol (c) tiron, and (d) copper nitrate scavengers.

The calculation of CI from the FTIR spectra (Figure S6) also confirmed the degradation of plastics. As observed in Table 3, the as-extracted MPs present a CI value of 0.86, which was related to chromophores' presence [26,36]. When photocatalysis is carried out without scavengers, MPs degradation led to an increase in the CI of $29 \%$. The CI values of the microbeads subjected to photocatalysis without $\mathrm{OH}^{\bullet}, h^{+}$, and $e^{-}$are similar to that of the as-extracted microplastics, while the MPs degraded in the absence of $\mathrm{O}_{2}{ }^{\bullet-}$ present an increase of $19 \%$ with respect to the pristine MPs. This intermediate value between the original and the most degraded MPs is in good agreement with reducing the HDPE concentration observed for this particular reaction system.

Table 3. Comparison of the CI of the as-extracted HDPE MPs with those subjected to visible-light photocatalytic degradation by $\mathrm{C}, \mathrm{N}-\mathrm{TiO}_{2}$ in the presence of scavengers.

\begin{tabular}{ccc}
\hline HDPE MPs & MPs' Degradation $\mathbf{( \% )}^{\prime}$ & CI $\left(\mathbf{A}_{\mathbf{1 7 2 0}} / \mathbf{A}_{\mathbf{1 3 8 0}}\right)$ \\
\hline As-extracted & - & 0.86 \\
\hline Without scavengers & $71.77 \pm 1.88[13]$ & 1.11 \\
\hline With $\mathrm{OH}^{\bullet}$ scavenger & $1.98 \pm 0.60$ & 0.85 \\
\hline With $h^{+}$scavenger & $2.53 \pm 1.00$ & 0.80 \\
\hline With $\mathrm{O}_{2}^{\bullet}-$ scavenger & $37.98 \pm 1.98$ & 1.03 \\
\hline With $e^{-}$scavenger & $1.62 \pm 0.10$ & 0.70 \\
\hline
\end{tabular}

\subsection{Proposed Mechanism for HDPE MPs Photocatalytic Degradation}

The proposed mechanism for PE degradation is presented in Scheme 1. 
As previously reported in the literature, in the initiation step the $\mathrm{OH}^{\bullet}$ break the $\mathrm{C}-\mathrm{H}$ bonds of the polymer backbone to produce polyethylene alkyl radicals $[36,45]$. The results suggest that the initiation step can also be promoted by the abstract of a hydrogen atom from the polymeric chain by $\mathrm{O}_{2}{ }^{\bullet-}$. This reaction's product is $\mathrm{HO}_{2}{ }^{\bullet}$, which form more $\mathrm{OH}^{\bullet}$ by the dismutation reaction presented in Equation (8). Moreover, the photo-Kolbe type reaction between the free electron-containing ending groups of the PE chain and the $h^{+}$ may also generate polyethylene alkyl radicals [41]. During propagation, the alkyl radicals react with $\mathrm{O}_{2}$ to generate peroxy radicals $\left(-\mathrm{CH}_{2}-\mathrm{CH}_{2}-\mathrm{HCOO}-\mathrm{CH}_{2}-\mathrm{CH}_{2}-\right)$, which form the hydroperoxide species $\left(-\mathrm{CH}_{2}-\mathrm{CH}_{2}-\mathrm{HCOOH}-\mathrm{CH}_{2}-\mathrm{CH}_{2}-\right)$ by extracting a hydrogen atom from another polymer chain. This chemical specie is further divided into two new free oxy and $\mathrm{OH}^{\bullet}$ radicals by the scission of the weak $\mathrm{O}-\mathrm{O}$ bond [46,47]. After the formation of hydroperoxides, complex radical reactions take place and lead to autoxidation. The propagation step leads to chain scission or crosslinking, promoting a decrease or increase in molecular weight. Finally, termination of the radical reaction takes place when the combination of two radicals forms inert products such as alkenes, aldehydes, and ketones.

The results obtained here confirm that the photocatalysis of MPs is a complex phenomenon that strongly depends on the reaction system's particular characteristics. Due to their bigger size (relative to $\mathrm{C}, \mathrm{N}-\mathrm{TiO}_{2}$ particles), MPs do not adsorb on the semiconductor. Instead, the $\mathrm{C}, \mathrm{N}-\mathrm{TiO}_{2}$ powders adsorb on the plastic's surface. This phenomenon limits the interaction between MPs, $h^{+}$and $\mathrm{OH}^{\bullet}$ ads. Despite this drawback, MPs' oxidation is still possible thanks to the formation of $\mathrm{O}_{2}{ }^{\bullet-}$ and free $\mathrm{OH}^{\bullet}$ (Reactions 6 and 11). Since both species are generated from the reaction pathways involving the photogenerated $e^{-}$, the results presented in this work reveal for the first time that the photogenerated $e^{-}$ plays an essential role in the photocatalytic degradation of HDPE MPs. Furthermore, the degradation behaviors observed when $h^{+}$and $\mathrm{O}_{2}{ }^{\bullet-}$ were absent from the reaction system suggest that the initiating step of MPs degradation can be performed by $\mathrm{OH}^{\bullet}$ and the photogenerated $h^{+}$or $\mathrm{O}_{2}{ }^{--}$.

\section{Conclusions}

In this work, an in-depth analysis regarding the participation of $\mathrm{OH}^{\bullet}, h^{+}, \mathrm{O}_{2}{ }^{\bullet-}$ and $e^{-}$in the photocatalytic degradation of primary HDPE MPs by $\mathrm{C}, \mathrm{N}-\mathrm{TiO}_{2}$ powders was performed using scavengers. The information presented in this work can contribute to the proper design of effective photocatalytic reaction systems that enhance the degradation of HDPE MPs. As the species adsorbed in the photocatalyst's surface have less contribution to degradation due to their limited interaction with the microbeads, degradation should be mainly based on the generation of free $\mathrm{OH}^{\bullet}$ in the bulk of the solution. This can be achieved, for example, by using photocatalysts specifically designed for avoiding $h^{+}-e^{-}$ recombination and well-oxygenated reaction mediums that enhance the $\mathrm{OH}^{\bullet}$ generation from the $e^{-}$-derived reaction pathways. Additionally, photocatalysis can be performed in solar light to further promote the generation of free $\mathrm{OH}^{\bullet}$ from the photolysis of $\mathrm{H}_{2} \mathrm{O}_{2}$.

Supplementary Materials: The following are available online at https:/ / www.mdpi.com/2073-436 0/13/7/999/s1, Figure S1: (a) Reflectance spectra and (b) Plot of $\left(\mathrm{F}(\mathrm{R})^{*} h v\right)^{1 / 2}$ vs. $h v$ of the $\mathrm{C}, \mathrm{N}-\mathrm{TiO}_{2}$ photocatalyst. Figure S2. $\mathrm{N}_{2}$ adsorption-desorption isotherms of the $\mathrm{C}, \mathrm{N}-\mathrm{TiO}_{2}$ photocatalyst. Figure S3. SEM-EDS analysis of the as-extracted HDPE MPs. Figure S4 SEM-EDS analysis of the HDPE MPs after photocatalysis at $0{ }^{\circ} \mathrm{C}$ and $\mathrm{pH} 3$ for $50 \mathrm{~h}$. Figure S5. SEM micrograph of the HDPE MPs after photocatalysis at $0{ }^{\circ} \mathrm{C}$ and $\mathrm{pH} 3$ for $50 \mathrm{~h}$ (high magnification). Table S1. EDS chemical microanalysis of the HDPE MPs after photocatalysis at $0^{\circ} \mathrm{C}$ and $\mathrm{pH} 3$ for $50 \mathrm{~h}$. Figure S6. FTIR spectra of the HDPE MPs before and after $50 \mathrm{~h}$ of photocatalytic degradation with and without scavengers.

Author Contributions: Conceptualization, E.I.C.-G.; Funding acquisition, E.I.C.-G. and J.F.V.-C.; Investigation, A.D.V.-G., M.C.A.-T. and V.M.L.-H.; Methodology, E.I.C.-G. and M.C.A.-T.; Supervision, E.I.C.-G., C.S., J.F.V.-C. and J.M.H.-L.; Project administration, E.I.C.-G.; Resources, E.I.C.-G., J.M.H.-L. and C.S.; writing-original draft preparation, A.D.V.-G., M.C.A.-T. and E.I.C.-G.; writing-review and editing, E.I.C.-G., C.S., J.M.H.-L. and J.F.V.-C. All authors have read and agreed to the published version of the manuscript. 
Funding: This research was funded by Mexican Council for Science and Technology (CONACYT), grant number PN-2017/5167, Program for Teacher Professional Development for the Superior Type of Mexican Secretary of Public Education, grant number 511-6/18-892 and UANL's PAICYT, grant number IT1277-20. The APC was funded by Universidad Autónoma de Nuevo León.

Institutional Review Board Statement: Not applicable.

Informed Consent Statement: Not applicable.

Data Availability Statement: The data presented in this study are available on request from the corresponding authors.

Acknowledgments: Authors thank the technical support of Paola Miselli from University of Modena and Reggio Emilia for her help with SEM-EDS analysis. Special thanks are given to David Adrian Garza Tamez from the Universidad Autónoma de Nuevo León for his help with performing some experiments.

Conflicts of Interest: The authors declare no conflict of interest. The funders had no role in the design of the study; in the collection, analyses, or interpretation of data; in the writing of the manuscript, or in the decision to publish the results.

\section{References}

1. Sharma, S.; Basu, S.; Shetti, N.P.; Nadagouda, M.N.; Aminabhavi, T.M. Microplastics in the environment: Occurrence, perils, and eradication. Chem. Eng. J. 2020, 408, 127317. [CrossRef]

2. Barceló, D.; Picó, Y. Microplastics in the global aquatic environment: Analysis, effects, remediation and policy solutions. J. Environ. Chem. Eng. 2019, 7, 103421. [CrossRef]

3. Wang, Y.; Wang, X.; Li, Y.; Li, J.; Liu, Y.; Xia, S.; Zhao, J. Effects of exposure of polyethylene microplastics to air, water and soil on their adsorption behaviors for copper and tetracycline. Chem. Eng. J. 2021, 404, 126412. [CrossRef]

4. Schwabl, P.; Koppel, S.; Konigshofer, P.; Bucsics, T.; Trauner, M.; Reiberger, T.; Liebmann, B. Detection of Various Microplastics inHuman Stool: A Prospective Case Series. Ann. Intern. Med. 2019, 171, 453-457. [CrossRef] [PubMed]

5. Ragusa, A.; Svelato, A.; Santacroce, C.; Catalano, P.; Notarstefano, V.; Carnevali, O.; Papa, F.; Rongioletti, M.C.A.; Baiocco, F.; Draghi, S.; et al. Plasticenta: First evidence of microplastics in human placenta. Environ. Int. 2021, 146, 106274. [CrossRef] [PubMed]

6. Fadare, O.O.; Okoffo, E.D. Covid-19 face masks: A potential source of microplastic fibers in the environment. Sci. Total Environ. 2020, 737, 140279. [CrossRef] [PubMed]

7. Habib, S.; Iruthayam, A.; Shukor, M.Y.A.; Alias, S.A.; Smykla, J.; Yasid, N.A. Biodeterioration of Untreated Polypropylene Microplastic Particles by Antarctic Bacteria. Polymers 2020, 12, 2616. [CrossRef]

8. Padervand, M.; Lichtfouse, E.; Robert, D.; Wang, C. Removal of microplastics from the environment. A review. Environ. Chem. Lett. 2020, 18, 807-828. [CrossRef]

9. Fujishima, A.; Zhang, X.; Tryk, D.A. TiO 2 photocatalysis and related surface phenomena. Surf. Sci. Rep. 2008, 63, 515-582. [CrossRef]

10. Uheida, A.; Mejía, H.G.; Abdel-Rehim, M.; Hamd, W.; Dutta, J. Visible light photocatalytic degradation of polypropylene microplastics in a continuous water flow system. J. Hazard. Mater. 2021, 406, 124299. [CrossRef]

11. Jiang, R.; Lu, G.; Yan, Z.; Liu, J.; Wu, D.; Wang, Y. Microplastic degradation by hydroxy-rich bismuth oxychloride. J. Hazard. Mater. 2021, 405, 124247. [CrossRef]

12. Zhang, Z.; Chen, Y. Effects of microplastics on wastewater and sewage sludge treatment and their removal: A review. Chem. Eng. J. 2020, 382, 122955. [CrossRef]

13. Ariza-Tarazona, M.C.; Villarreal-Chiu, J.F.; Hernández-López, J.M.; De la Rosa, J.R.; Barbieri, V.; Siligardi, C.; Cedillo-González, E.I. Microplastic pollution reduction by a carbon and nitrogen-doped $\mathrm{TiO}_{2}$ : Effect of $\mathrm{pH}$ and temperature in the photocatalytic degradation process. J. Hazard. Mater. 2020, 395, 122632. [CrossRef]

14. Ariza-Tarazona, M.C.; Villarreal-Chiu, J.F.; Barbieri, V.; Siligardi, C.; Cedillo-González, E.I. New Strategy for Microplastic Degradation: Green Photocatalysis Using a Protein-Based Porous N-TiO 2 Semiconductor. Ceram. Int. 2019, 45, 9618-9624. [CrossRef]

15. Llorente-García, B.E.; Hernández-López, J.M.; Zaldívar-Cadena, A.A.; Siligardi, C.; Cedillo-González, E.I. First Insights into Photocatalytic Degradation of HDPE and LDPE Microplastics by a Mesoporous $\mathrm{N}-\mathrm{TiO}_{2}$ Coating: Effect of Size and Shape of Microplastics. Coatings 2020, 10, 658. [CrossRef]

16. Razali, N.; Terengganu, U.M.; Abdullah, W.R.W.; Zikir, N.M. Effect of thermo-photocatalytic process using zinc oxide on degradation of macro/micro-plastic in aqueous environment. J. Sustain. Sci. Manag. 2020, 15, 1-14. [CrossRef]

17. Tofa, T.S.; Ye, F.; Kunjali, K.L.; Dutta, J. Enhanced Visible Light Photodegradation of Microplastic Fragments with Plasmonic Platinum/Zinc Oxide Nanorod Photocatalysts. Catalysts 2019, 9, 819. [CrossRef] 
18. Nabi, I.; Bacha, A.-U.-R.; Li, K.; Cheng, H.; Wang, T.; Liu, Y.; Ajmal, S.; Yang, Y.; Feng, Y.; Zhang, L. Complete Photocatalytic Mineralization of Microplastic on $\mathrm{TiO}_{2}$ Nanoparticle Film. iScience 2020, 23, 101326. [CrossRef]

19. Domínguez-Jaimes, L.P.; Cedillo-González, E.I.; Luévano-Hipólito, E.; Acuña-Bedoya, J.D.; Hernández-López, J.M. Degrada-tion of primary nanoplastics by photocatalysis using different anodized $\mathrm{TiO}_{2}$ structures. J. Hazard. Mater. 2021, 413, 125452. [CrossRef]

20. Napper, I.E.; Bakir, A.; Rowland, S.J.; Thompson, R.C. Characterisation, quantity and sorptive properties of microplastics extracted from cosmetics. Mar. Pollut. Bull. 2015, 99, 178-185. [CrossRef] [PubMed]

21. Zeng, H.; Xie, J.; Xie, H.; Su, B.-L.; Wang, M.; Ping, H.; Wang, W.; Wang, H.; Fu, Z. Bioprocess-inspired synthesis of hierarchically porous nitrogen-doped $\mathrm{TiO}_{2}$ with high visible-light photocatalytic activity. J. Mater. Chem. A 2015, 3, 19588-19596. [CrossRef]

22. Rodríguez, E.M.; Márquez, G.; Tena, M.; Álvarez, P.M.; Beltrán, F.J. Determination of main species involved in the first steps of $\mathrm{TiO}_{2}$ photocatalytic degradation of organics with the use of scavengers: The case of ofloxacin. Appl. Catal. B Environ. 2015, 178, 44-53. [CrossRef]

23. Pelaez, M.; Falaras, P.; Likodimos, V.; O'Shea, K.; de la Cruz, A.A.; Dunlop, P.S.M.; Byrne, J.A.; Dionysiou, D.D. Use of selected scavengers for the determination of $\mathrm{NF}^{-\mathrm{TiO}_{2}}$ reactive oxygen species during the degradation of microcystin-LA under visible light irradiation. J. Mol. Catal. A Chem. 2016, 425, 183-189. [CrossRef]

24. Chamas, A.; Moon, H.; Zheng, J.; Qiu, Y.; Tabassum, T.; Jang, J.H.; Abu-Omar, M.M.; Scott, S.L.; Suh, S. Degradation Rates of Plastics in the Environment. ACS Sustain. Chem. Eng. 2020, 8, 3494-3511. [CrossRef]

25. Davidson, R.; Meek, R. The photodegradation of polyethylene and polypropylene in the presence and absence of added titanium dioxide. Eur. Polym. J. 1981, 17, 163-167. [CrossRef]

26. Ali, S.S.; Qazi, I.A.; Arshad, M.; Khan, Z.; Voice, T.C.; Mehmood, C.T. Photocatalytic degradation of low density polyethylene (LDPE) films using titania nanotubes. Environ. Nanotechnol. Monit. Manag. 2016, 5, 44-53. [CrossRef]

27. Socrates, G. Infrared and Raman Characteristic Group Frequencies: Tables and Charts, 3rd ed.; John Wiley \& Sons: Hoboken, NJ, USA, 2004; ISBN 9780470093078.

28. Yu, J.-G.; Yu, H.-G.; Cheng, B.; Zhao, X.-J.; Yu, J.C.; Ho, W.-K. The Effect of Calcination Temperature on the Surface Microstructure and Photocatalytic Activity of $\mathrm{TiO}_{2}$ Thin Films Prepared by Liquid Phase Deposition. J. Phys. Chem. B 2003, 107, 13871-13879. [CrossRef]

29. Zhang, J.; Zhou, P.; Liu, J.; Yu, J. New understanding of the difference of photocatalytic activity among anatase, rutile and brookite $\mathrm{TiO}_{2}$. Phys. Chem. Chem. Phys. 2014, 16, 20382-20386. [CrossRef] [PubMed]

30. Li, G.; Richter, C.P.; Milot, R.L.; Cai, L.; Schmuttenmaer, C.A.; Crabtree, R.H.; Brudvig, G.W.; Batista, V.S. Synergistic effect between anatase and rutile $\mathrm{TiO}_{2}$ nanoparticles in dye-sensitized solar cells. Dalton Trans. 2009, 10078-10085. [CrossRef]

31. Huo, Y.; Jin, Y.; Zhu, J.; Li, H. Highly active $\mathrm{TiO}_{2}-\mathrm{X}-\mathrm{yNxFyvisible} \mathrm{photocatalyst} \mathrm{prepared} \mathrm{under} \mathrm{supercritical} \mathrm{conditions} \mathrm{in}$ $\mathrm{NH}_{4} \mathrm{~F} /$ EtOH fluid. Appl. Catal. B Environ. 2009, 89, 543-550. [CrossRef]

32. Yang, G.; Jiang, Z.; Shi, H.; Xiao, T.; Yan, Z. Preparation of highly visible-light active N-doped TiO 2 photocatalyst. J. Mater. Chem. 2010, 20, 5301-5309. [CrossRef]

33. Yurdakal, S.; Garlisi, C.; Özcan, L.; Bellardita, M.; Palmisano, G. (Photo)catalyst characterization techniques: Adsorption isotherms and BET, SEM, FTIR, UV-Vis, photoluminescence, and electrochemical characterizations. In Heterogeneous Photocatalysis: Relationships with Heterogeneous Catalysis and Perspectives, 1st ed.; Marcì, G., Palmisano, L., Eds.; Elsevier: Amsterdam, The Netherlands, 2019; pp. 87-152, ISBN 9780444640154.

34. Bezerra, P.; Cavalcante, R.; Garcia, A.; Wender, H.; Martines, M.; Casagrande, G.; Giménez, J.; Marco, P.; Oliveira, S.; Machulek, A., Jr. Synthesis, Characterization, and Photocatalytic Activity of Pure and N-, B-, or Ag- Doped TiO 2 . J. Braz. Chem. Soc. 2017, 28, 1788-1802. [CrossRef]

35. Du, Y.; Rabani, J. The Measure of $\mathrm{TiO}_{2}$ Photocatalytic Efficiency and the Comparison of Different Photocatalytic Titania. J. Phys. Chem. B 2003, 107, 11970-11978. [CrossRef]

36. Tofa, T.S.; Kunjali, K.L.; Paul, S.; Dutta, J. Visible light photocatalytic degradation of microplastic residues with zinc oxide nanorods. Environ. Chem. Lett. 2019, 17, 1341-1346. [CrossRef]

37. Mills, A.; Lee, S.-K. A web-based overview of semiconductor photochemistry-based current commercial applications. J. Photochem. Photobiol. A Chem. 2002, 152, 233-247. [CrossRef]

38. Uekert, T.; Kasap, H.; Reisner, E. Photoreforming of Nonrecyclable Plastic Waste over a Carbon Nitride/Nickel Phosphide Catalyst. J. Am. Chem. Soc. 2019, 141, 15201-15210. [CrossRef] [PubMed]

39. Arsac, F.; Bianchi, D.; Chovelon, J.M.; Ferronato, C.; Herrmann, J.M. Experimental Microkinetic Approach of the Photocatalytic Oxidation of Isopropyl Alcohol on $\mathrm{TiO}_{2}$. Part 1. Surface Elementary Steps Involving Gaseous and Adsorbed $\mathrm{C}_{3} \mathrm{HxO}$ Species. J. Phys. Chem. A 2006, 110, 4202-4212. [CrossRef]

40. Giles, H.F.; Wagner, J.R.; Mount, E.M. Polymer Overview and Definitions. Extrusion 2005, 165-177. [CrossRef]

41. Yang, R.; Christensen, P.A.; Egerton, T.A.; White, J.R. Degradation products formed during UV exposure of polyethylene-ZnO nano-composites. Polym. Degrad. Stab. 2010, 95, 1533-1541. [CrossRef]

42. Alegría, A.E.; Ferrer, A.; Santiago, G.; Sepúlveda, E.; Flores, W. Photochemistry of water-soluble quinones. Production of the hydroxyl radical, singlet oxygen and the superoxide ion. J. Photochem. Photobiol. A Chem. 1999, 127, 57-65. [CrossRef]

43. Garg, S.; Rose, A.L.; Waite, T.D. Production of Reactive Oxygen Species on Photolysis of Dilute Aqueous Quinone Solutions. Photochem. Photobiol. 2007, 83, 904-913. [CrossRef] 
44. Hayyan, M.; Hashim, M.A.; Alnashef, I.M. Superoxide Ion: Generation and Chemical Implications. Chem. Rev. 2016, 116, 3029-3085. [CrossRef] [PubMed]

45. Gewert, B.; Plassmann, M.M.; MacLeod, M. Pathways for degradation of plastic polymers floating in the marine environment. Environ. Sci. Process. Impacts 2015, 17, 1513-1521. [CrossRef] [PubMed]

46. Kriston, I. Some Aspects of the Degradation and Stabilization of Phillips Type Polyethylene. Ph.D. Thesis, Budapest University of Technology and Economics, Budapest, Hungary, 26 April 2011.

47. Fotopoulou, K.N.; Karapanagioti, H.K. Degradation of Various Plastics in the Environment. In Hazardous Chemicals Associated with Plastics in the Marine Environment, 1st ed.; Takada, H., Karapanagioti, H., Eds.; Springer: Cham, Switzerland, 2019 ; pp. 71-92. 